\title{
Six Sigma applied in inventory management
}

\author{
Biao $\mathrm{Hu}^{1, a}$, Yun Tian ${ }^{2, b}$ \\ ${ }^{1}$ School of management Tianjin University of Technology Tianjin, China \\ ${ }^{2}$ School of management Tianjin University of Technology Tianjin, China \\ ahubiaomail@126.com, btianyunty_001@163.com
}

\begin{abstract}
Keywords: inventory management; Six Sigma Management; process improvement.
\end{abstract}
Abstract. Inventory management is a kind of method used by manufacturing or service sector to manage and control various articles and other resources in the whole process of production and operation. This paper, aiming at the contradiction, brings forward the thought of combining Six Sigma Concept with inventory management. Using Six Sigma Tools, the root source of inventory overstock will be revealed and according process can be improved, thus to achieve the goal of inventory optimizing and customer satisfactory elevating. An actual example is demonstrated in the paper to verify the validity of the combination between inventory management and Six Sigma.

\section{Inventory Management and Its Current Situation}

A. Inventory and inventory management

From the logistics point of view, inventory is temporarily the idle resources of economic value in order to meet the future needs, is storage of various materials for the purpose of supporting the production, maintenance, operations and customer service, including raw materials and the products, repair parts and production supplies, finished products and spare parts.In principle, any business needs some level of inventory to meet the possible fluctuations in the production and sales process; but excess inventory easily make enterprises get into the situation of cash flow problems [1].

B. Current situation of inventory management

Inventory control methods dominate the current study of inventory management, the core idea is that inventory costs will be divided into the ordering cost, inventory holding cost, stock cost and purchase cost, shortage costs, associated capacity cost and other parts starting from the inventory costs, making the optimal solution of the order point and order quantity through the establishment of mathematical model, and making ordering policy according to the optimal solution.

Overall, the input of the inventory model is the forecast of demand, and the output is the order strategy according to the process of mathematical programming, which is shown in Fig. 1.

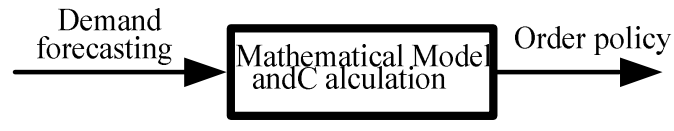

Fig.1 Flowchart of the method of inventory control

The current inventory management is lack of the customer-centric and process-oriented philosophy, so it is necessary to combine some management concepts and methods. The philosophy of Six Sigma management is an effective management approach to solve the problem from the root causes, which is based on the idea of process improvement, accurately grasp the voice of the customer, and tap the real problem.

\section{The Concept of Six Sigma Management}

The idea of Six Sigma [6] originated in the 20th century, proposed first by Motorola in United States; the mid-90s, it was widely used and developed in the U.S. General Electric (GE) and reached a great success. Thus it is recognized and used by more and more enterprises are.

Six Sigma Management is a management approach which can significantly improve business process performance through designing and monitoring of daily business processes, reducing the loss of resources and improving customer satisfaction. Its core idea is: the customer demand-driven, promote 
process improvement ideas, talking with facts and data, the pursuit of continuous improvement and financial performance. The implementation model of this method in the manufacturing sector is the main method of Six Sigma improvement DMAIC [4]. DMAIC represents the five stages of Six Sigma management: definition, measurement, analysis, improvement and control. Each stage has a number of steps by the composition [7].

\section{The Cases Study}

\section{A. Project Background}

$\mathrm{L}$ is a company specialized in manufacturing auto parts and processing enterprises. With the increase in business volume, $\mathrm{L}$ is facing the same problem of other large manufacturing enterprises: inventory increased every year, reducing the cash flow rate, taking a lot of storage space, increasing the cost of capital. Although the strategy developed for the ordering method of inventory control changed again and again, the problem did not overstock significantly improved. Instead, as using the algorithm which is more and more complex, cost increases much more.

B. The improvement of project process

1) D-Definition stage

At this stage, the team must clear the project customers, goals, time of completion, the team members and their respective responsibilities, to lay the foundation for smooth implementation of the project. The preparatory phase consists of three steps (not included 12 steps of DMAIC).

(1) Identification of the key points of customer quality (CTQ)

The project CTQ includes: raw materials and in-process inventory should be sufficient to ensure the continued operation of production; inventory should be controlled at a low level, thereby enhancing the cash flow rate and reduce the cost of capital; finished goods inventory should be sufficient to ensure the delivery rate.

(2) Building Team Charter

In this step, the team should aim to develop a preliminary statement of problems, to assess the project scope and completion time, to select team members and assign roles.

(3)Drawing the order flowchart

The company's inventory level of L depends largely on traffic flow and the streamline of process. L Company's original order process is shown in Fig. 2.

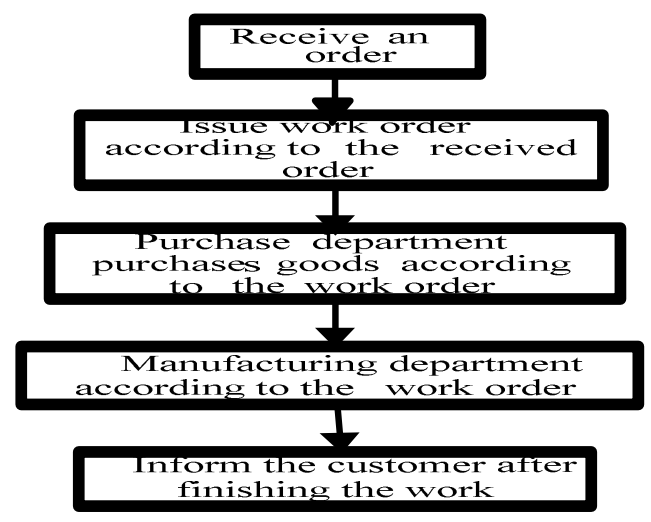

Fig. 2 The original order flow

2) $\mathrm{M}$-Measurement stage

Step1. Select the key quality characteristics

In this step, we need to change the key quality of customers into the features of the quality which the organization can control and improve. Represent the features with a functional form, which is $Y=f\left(y_{1}, y_{2}, \ldots, y_{n}\right)$. What we have to do is to identify these variables.

We use quality function deployment to identify key quality characteristics, as shown in Table 1. 
Table 1 The final weight table of Quality Function Deployment

\begin{tabular}{|c|c|c|c|c|c|c|c|}
\hline Y & weight & $\begin{array}{c}\text { delivery } \\
\text { rate }\end{array}$ & plan & $\begin{array}{c}\text { materials } \\
\text { costs }\end{array}$ & $\begin{array}{c}\text { reduce costs of } \\
\text { materials }\end{array}$ & $\begin{array}{c}\text { reduce running } \\
\text { costs }\end{array}$ & Total \\
\hline $\mathrm{c}$ & 5 & 5 & 5 & 1 & 1 & 1 & 65 \\
\hline $\mathrm{d}$ & 3 & 1 & 5 & 3 & 1 & 1 & 33 \\
\hline $\mathrm{e}$ & 5 & 3 & 3 & 5 & 5 & 5 & 105 \\
\hline \multicolumn{2}{r}{ Total } & 43 & 39 & 35 & 29 & 27 & \\
\hline
\end{tabular}

c: Just-in-time delivery; d: Ensure continuous operation of the production process; e: Maintain the turnover rate of funds at a certain level

From Table 1, we can see that "ensure the delivery rate at a certain level", "Accurate production and purchasing plan" and "maintain inventory at a lower level" are the three heaviest weight operational measurements which are the three key $y_{i}$

Step 2 Define performance standards of the performance index

In the step 1, we identified the key quality characteristics. We need to design the evaluation index and measurement standards of these quality characteristics in step 2. According to three key quality characteristics identified in the previous step, we determine the evaluation index and measurement standards shown in the Table 2.

Table 2 The evaluation index and Measurement Standard

\begin{tabular}{|c|c|c|c|c|}
\hline & Content & defect rate & Objects & $\begin{array}{c}\text { Number of } \\
\text { opportunities }\end{array}$ \\
\hline$y_{1}$ & Just-in-time delivery & Less than $85 \%$ & $\begin{array}{c}\text { The total delivery batch } \\
\text { each week }\end{array}$ & $\begin{array}{c}\text { Every object has one } \\
\text { opportunity }\end{array}$ \\
\hline$y_{2}$ & $\begin{array}{c}\text { Continuous working time of } \\
\text { production line }\end{array}$ & $\begin{array}{c}\text { Less than } 8 \text { hours for } \\
\text { goods' shortage }\end{array}$ & Each frequency & $\begin{array}{c}\text { Every object has one } \\
\text { opportunity }\end{array}$ \\
\hline$y_{3}$ & $\begin{array}{c}\text { The average amount of } \\
\text { inventory }\end{array}$ & $\begin{array}{c}\text { More than 120 thousand } \\
\text { Yuan per Month }\end{array}$ & $\begin{array}{c}\text { Stocktaking once a } \\
\text { month }\end{array}$ & $\begin{array}{c}\text { Every object has one } \\
\text { opportunity }\end{array}$ \\
\hline
\end{tabular}

Step3. Establish a data-collection plan

The project of $6 \sigma$ is strictly based on facts and data, so the accuracy of the data collected plays a decisive role in the success of the project. In addition to collecting the right data, the accuracy of the measurement system plays a very key role in the accuracy of the data.

3) A-Analysis stage

Step4. Determine the process capability

In this project, according to the three quality characteristics and performance standards described previously, the team collected 6-month data and obtain the process capability through Minitab which are summarized in Table 3:

Table 3 Process Capability of key quality characteristics

\begin{tabular}{|l|c|c|c|}
\hline & Content & Sigma (Z.Bench) & DPMO \\
\hline$y_{1}$ & Just-in-time delivery rate & -0.96 & 837002.3 \\
\hline$y_{2}$ & Continuous working time of production line & -0.92 & 821210.9 \\
\hline$y_{3}$ & The average amount of inventory & -1.21 & 887777.3 \\
\hline
\end{tabular}

Then we can see the three process capability of quality characteristics are very low and are all negative, but the defect rates of millions of opportunities are very high and are all more than 800 thousand.

Step 5. To develop the target performance standards for process

On the basis of getting the existing baseline of the process in the performance, the team should determine the target for improvement.

In this project, after two considerations the company should determine the improving goal of opportunities for millions of defect rate decreased to 10 million or less, that is about $87.5 \%$ improvement and make the improvements and efforts to achieve the 10000-20000DPMO's industry-leading level

Step6. Identification the sources of volatility

The team enumerates the various causes of leading to high inventories and the delivery period did not shorten at the same time through brainstorming and draws the Fish-bone Chart shown in Fig. 3. 


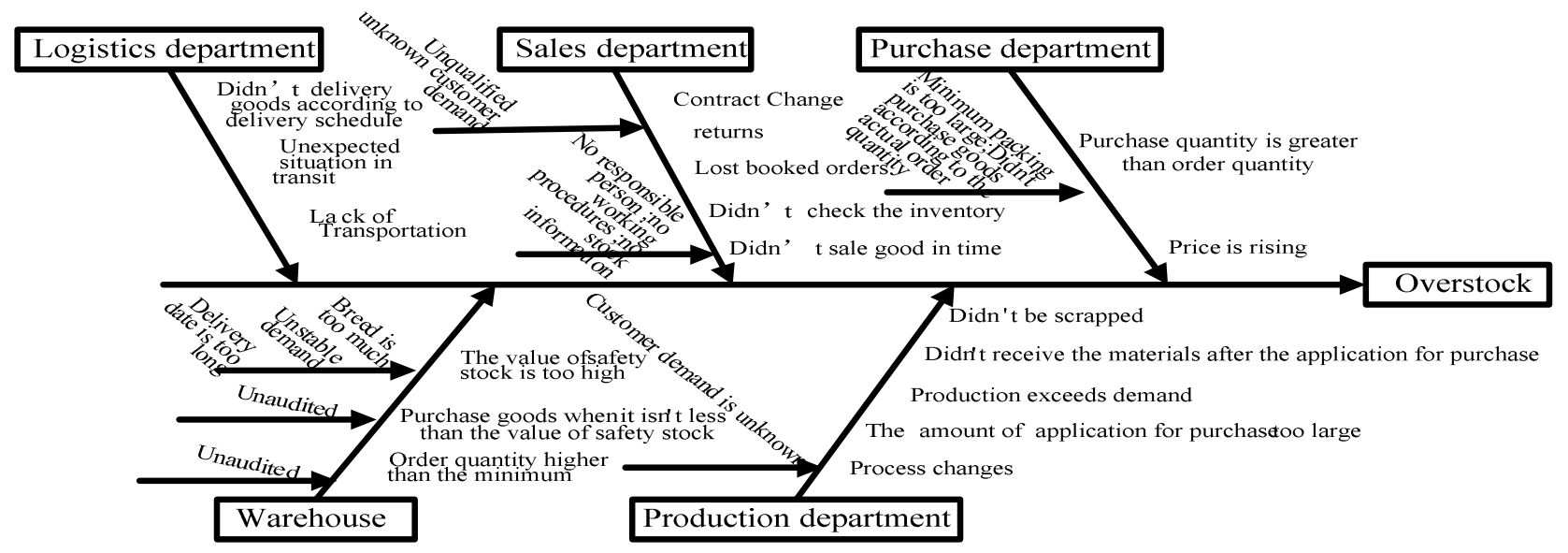

Fig.3 The Fishbone Diagram of overstock

4) I-Improvement stage

Step7. Screening of the potential causes

From the analysis we know that the orders, purchasing, sales and manufacturing are lack of communication with each other, and the order flow stock's obstruction is the main reason of the backlog.

Step8. Find the relationship between variables and propose a solution

According to the conclusions of Step7, we get the process changes as shown in Fig. 4.

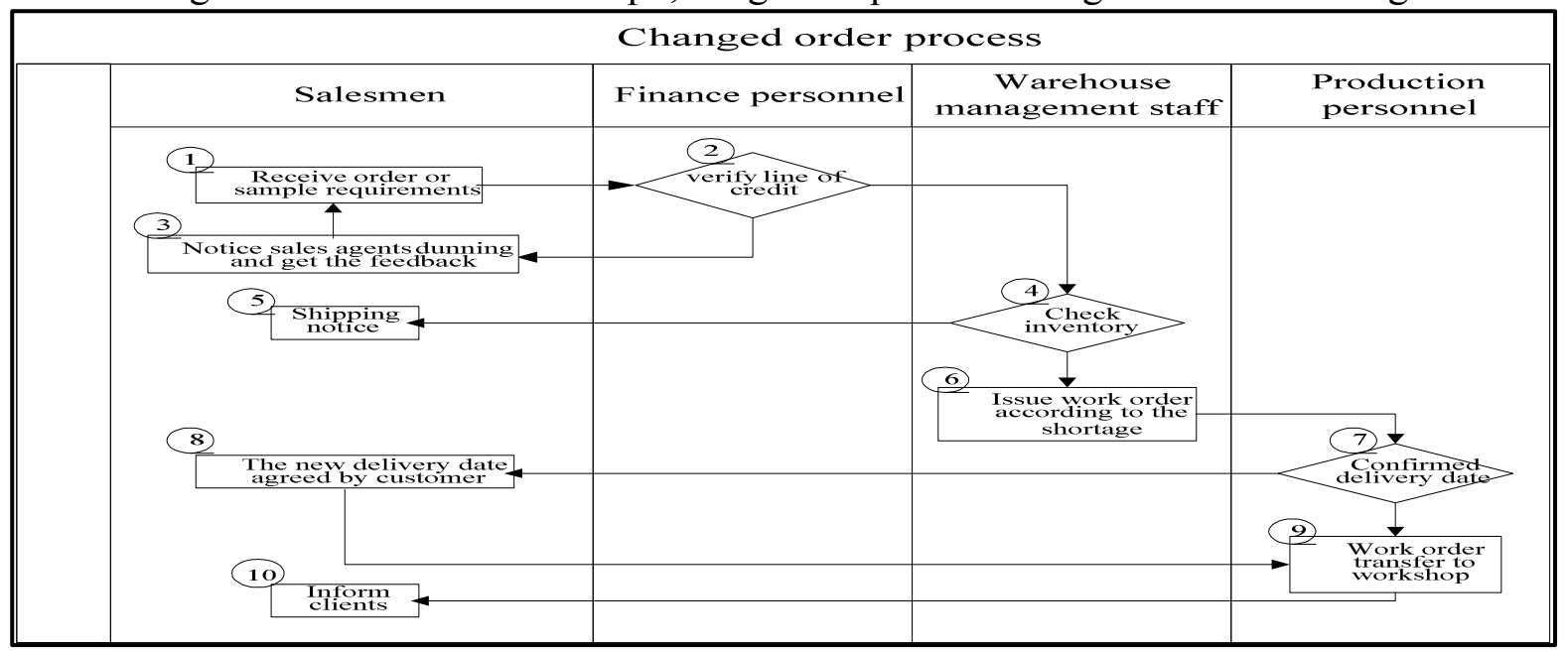

Step9. Execute solution

Fig.4 Changed order process

In this project, we use new process to complete the order management, and try it for 3 months.

5) $\mathrm{C}$ - Control stage

Step10. Verify and measure system

Before measuring the capacity of the process, it is also necessary to test the measure system of collecting the data and verify its effectiveness.

Step11. Ascertain the improved process capability

Collect the three-month data of execution process improvements. And measure the process capacity of the three key quality characters, which is shown in Table 4

Table 4 Process Capability of key quality characteristics improved

\begin{tabular}{|c|c|c|c|}
\hline \multirow{2}{*}{} & & \multicolumn{2}{|c|}{ Process Benchmarks } \\
\cline { 3 - 4 } & & Actual(LT) & Potential(ST) \\
\hline \multirow{2}{*}{ Improved $y_{1}$} & Sigma(Z.Bench) & 1.65 & 3.15 \\
\cline { 2 - 4 } & DPMO & 49662.0 & 821.6 \\
\hline \multirow{2}{*}{ Improved $y_{2}$} & Sigma(Z.Bench) & 2.07 & 3.57 \\
\cline { 2 - 4 } & DPMO & 19067.7 & 176.2 \\
\hline \multirow{2}{*}{ Improved $y_{3}$} & Sigma(Z.Bench) & 2.06 & 3.56 \\
\cline { 2 - 4 } & DPMO & 19550.9 & 183.2 \\
\hline
\end{tabular}


From the table above, we can see that the improved quality-characteristic indicators of DPMO are controlled less than 100 thousand. The index of the production duration and inventory cost are less than 20 thousand DPMO, achieving the high level of the same industry. Therefore, it is considered valid that the improved process is talked in this paper.

Step12. Control system of executive process

The new process has been implemented for one year, and the economic benefits are significant, which can be shown in Table 5 .

Table 5 Economic-benefit table of the project implementation [k\$]

\begin{tabular}{|c|c|c|c|c|c|c|c|c|}
\hline \multirow{3}{*}{ Project } & \multirow{2}{*}{\multicolumn{2}{|c|}{ Before improvement }} & \multirow{2}{*}{\multicolumn{2}{|c|}{ After improvement }} & \multicolumn{4}{|c|}{ Improved results } \\
\hline & & & & & \multicolumn{2}{|c|}{ Inventory } & \multicolumn{2}{|c|}{ Reject } \\
\hline & Inventory & Reject & Inventory & Reject & Amount & Proportion & Amount & Proportion \\
\hline 1 & 5099 & 27 & 3974 & 2 & 1125 & $22.06 \%$ & 25 & $92.59 \%$ \\
\hline 2 & 8295 & 26 & 6148 & 2 & 2147 & $25.88 \%$ & 24 & $92.31 \%$ \\
\hline 3 & 3792 & 666 & 2679 & 78 & 1113 & $29.35 \%$ & 588 & $88.29 \%$ \\
\hline Total & 17186 & 719 & 12801 & 82 & 4385 & $25.51 \%$ & 637 & $88.60 \%$ \\
\hline
\end{tabular}

Instruction: 1: raw material;2: finishing and semi-finished products;3: finished products

\section{Summary}

In today's increasingly competitive environment, it is paid more and more attention in reducing inventory costs which is as "the third profit source". However, the current inventory-control method usually focus on the optimization of specific mathematical models, while ignore the serious lag-plug influence of the business process on reducing inventory, making the company stock not reduced effectively.

According to this situation, this paper proposes necessity of implementing process improvement in inventory control; making the $6 \sigma$ thoughts blend into the inventory control. Above all, in this paper, the importance of the inventory management based on the $6 \sigma$ theory has been explained. The feasibility and effectiveness have been verified by an actual case.

In fact, mining thoughts of the problem's essence will have a significant impact on inventory control except the process improvement ideas in the Six Sigma theory. What's in earth the backlog of inventory due to internal process's mismatch, or the customer needs' misunderstanding, or the demand forecasting inaccuracy? Nevertheless, no matter what the answer is, the inventory management personnel should understand and optimize it for improvement by using the Six Sigma theory.

\section{References}

[1] Zuhua Jiang, Lifeng Xi, etc. Case Study for Industrial Engineering[M]. Beijing: Tsinghua University Press, pp.219-243, 2005.

[2] LEE H L, Padmanabhanv, Whangs. The Bullwhip Effect in Supply Chain[J]. Sloan Management Review, Vo1.38, pp. 93-102, 1997.

[3] Chen F, Drezner Z, Ryan J, etc. Quantifying the bullwhip effect in simple supply chain: The impact of forecasting, lead times, and information [J]. Management Science, Vo1. 46, No. 3, pp. 436-443, 2000.

[4] Peter S. Pande, etc. Six Sigma Management: Steps to excellence [M]. Beijing: Mechanical Industry Press, pp.201-212, 2002.

[5] Qingli Da, Xin Zhang, Hou-cai Shen. Study on bullwhip effect in supply chain [J]. Journal of Management Sciences, Vo1. 6, No. 3, pp. 86-93, 2003.

[6] Xiaoqun He. Six Sigma and Getting Started Guide [M]. Beijing: China Renmin University Press, pp. 4-52, 2003.

[7] Xiaofen Tang. Six Sigma Core Tutorial (Black Belt Reader)[M]. Beijing: Standards Press of China, pp. 307-320, 2002.

[8] Waters Donald. Inventory Control and Management [M]. Beijing: Mechanical Industry Press, 2005. 